\title{
Numerical Study of Sediment Flow Over Bottom Intake Racks With Flow-
} 3D

\author{
${ }^{1}$ Seyed Mahyar Zamanieh Shahri, ${ }^{2}$ Seyed Alireza Khoshnevis, ${ }^{3}$ Keivan Bina, ${ }^{4}$ Seyed Armin \\ Aboutalebi,
}

Department of Civil Engineering, Khavaran Institute of Higher Education, Mashhad, Iran Department of Electrical Engineering, University of South Florida, Tampa, USA.

Disaster Risk Reduction Advisor, Assistant Professor of Civil Engineering, Khavaran Institute of Higher

Education, Ghasem Abad, Mashhad, Iran.

Department of Civil Engineering, Azad University of Semnan, Semnan, Iran.

\begin{abstract}
:
Bottom intakes are the most useful structure for diverting the flow of steep rivers and providing specific amount of water for hydropower usage. It is crucial to obtain optimum of physical parameters in order to divert desired discharge with minimum possibility of occlusion. Numerical models can simulate flow and turbulence transport equations at any complex geometries. Numerical methods based on Computational Fluid Dynamics (CFD), are one of the most common methods of numerical simulation that is used in water structures. According to the capabilities of numerical methods, complex modes of flow field over bottom intakes can be analyzed. In the present study, Flow-3D software is used to investigate the experimental results of the previous researcher for sediment and clean water flow over bottom intake with circular bars numerically. This study is carried out in a total of 27 models for clean water and 9 models of sediment flow (Bed-Load) at different approaching flow conditions. Parameters of roughness, size of computational cell, turbulence transport equation, Bed Load Transport equation and bed load coefficient has been calibrated. Validation procedure proved that the accuracy and performance of numerical models appear to be acceptable for designing intake systems. For each test, the discharge coefficient is computed, then by using dimensional analysis, a dimensionless relation derived from the dependent and independent variables and compared with the measured discharge coefficient. Estimating the discharge coefficient by the proposed equation in clean water flow performed a mean error of 6.4 percent and for sediment flow led to a mean error of 4.3 percent.
\end{abstract}

Keywords: Bottom intake; small hydropower; Flow-3D software; circular bars; turbulent flow; bed load; discharge coefficient.

\section{Introduction}

Bottom intakes are structures that are used for diverting river flow generally for the goal of generating electricity in hydropower. The water is supplied from the small mountain rivers with steep slopes and intensive sediment transport. The intake structure must be simple from the construction point of view and requires less maintenance work after the construction. Bottom intakes must be able to divert the maximum flow discharge at all time with the minimum quantity of sediment and minimum possibility of occlusion. Bottom intake is the most suitable structure which can satisfy all the items mentioned above. This structure consists of a diversion channel below the river bed in on the side of the river, and a metal structure consists of bars on top of the diversion channel (Fig. 1). 


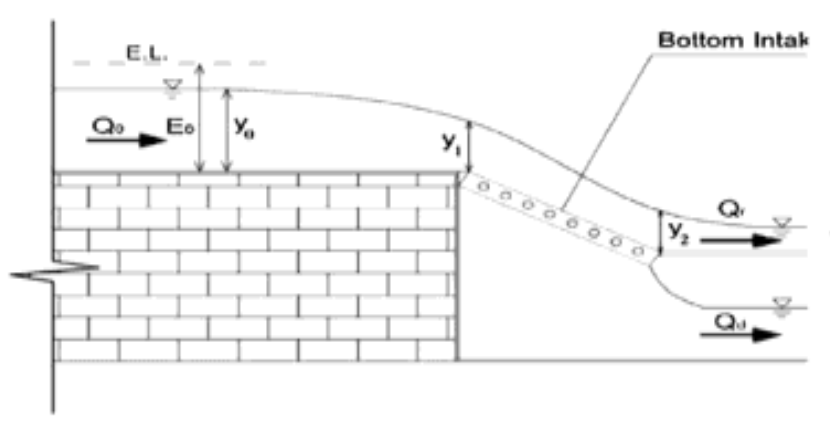

(a)

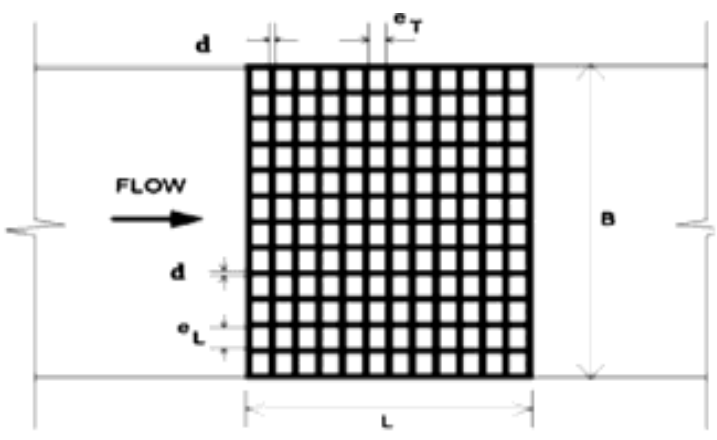

(b)

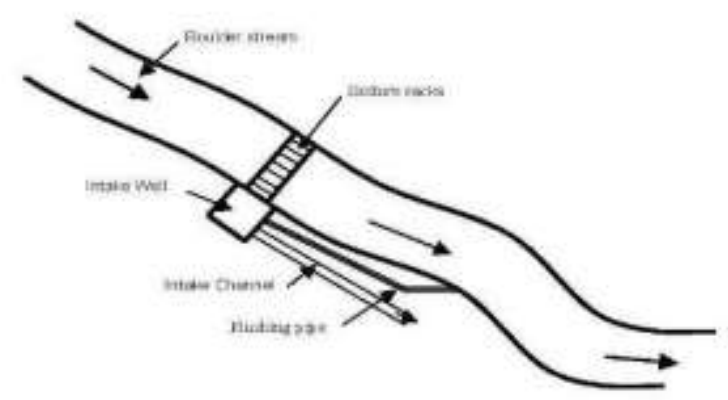

Figure 1. Sketch of the bottom intake structure.

Diversion channel transports the water to the penstock of hydropower. The function of bottom intakes is depended on different factors, such as approaching flow conditions, the size and shape of bars (shape function), the longitudinal slope, opening ratio (spacing between bars). Although this structure is the most useful structure for diverting river flow, some of its design criteria for optimum structure design needs to be studied. In the present study a rectangular channel with a circular opening in the bottom constructed to divert sediment and to produce an intake structure [12].

In the previous studies, there are some simplifying assumptions, such as hydrostatic pressure distribution over the racks in the flow direction, a progressive decrease of the flow during the bottom intake and onedimensional velocity factor over the bars. For simplifying the energy head, some authors considered a horizontal energy level over the bottom intake (Torabi et al. [24]; Vargas [23]; Brunella et al. [3]; Righetti \& Lanzoni [20]; Garcia [10]; Drobir et al. [7]) and others considered a parallel energy level (Noseda [17]; Dagan [6]; Hamedi et al. [25]).

Orth et al.[18] provided the first investigation of the flow field over bottom intake. Different flows on a $20 \%$ sloping channel with five different rack geometries, including the simple $\mathrm{T}$-shaped, the $\mathrm{T}$ with a top triangle profile, the semicircular bar, the circular bar and the ovoid profile was investigated. The ovoid bar profile had the least wetted length, where the t- shaped bar had the poorest diverting performance. The bottom slope of the rack had only a small effect on rack occlusion.

Righetti and Lanzoni [20] studied the hydraulic design of Bottom racks made by longitudinal bars, analyzing the data obtained from a systematic series of experiments carried out in a laboratory flume. For each run they measured the diverted discharge, the water surface longitudinal profile and they obtained discharge coefficient to be used to determine the rate of change of the diverted discharge. They also drove a physically based relationship relating the overall diverted discharge to the length of the rack, the void ratio, the discharge coefficient measured under static conditions, the specific head of the stream approaching the rack, and a modified Froude number. The robustness of the proposed relationship is confirmed by the comparison between the discharges calculated through the proposed relationship and those measured in an extensive series of experiments.

$\Delta \mathrm{Q}=C_{q o} \omega W L \sqrt{2 g H_{o}}\left(\frac{a}{2} \frac{L}{H_{o}} F_{H_{O}}+1\right) \tanh \left[b_{o}\left(\sqrt{2}-F_{H_{o}}\right)^{b_{1}}\right]$

Where the coefficients $b_{o}$ and $b_{1}$ appearing in the hyperbolic tangent were obtained by minimizing the sum of the errors between the computed and measured total discharge diverted (estimated value: $b_{o}=1.5$, 
$\left.\mathrm{b}_{1}=0.6093\right), \omega=$ void ratio, $\mathrm{W}=$ channel width, $C_{q o}=$ the experimental values measured under static conditions, $H_{o}=$ the specific head of the stream approaching the rack, $\mathrm{F}_{\mathrm{H}_{\mathrm{O}}}=$ modified Froude number.

Kumar and Ahmad [15] studied in the laboratory the percentage of solids passing through the rack. The authors considered the longitudinal rack slope, different water flows, the ratio between the size of sediments, and the bar clearance (from 0.18 to 0.83 ).

Brunella et al. [3] conducted experimental tests in a rectangular channel, $0.5 \mathrm{~m}$ wide and $7 \mathrm{~m}$ long. According to the extended laboratory observation, the effect of various parameters, such as the bottom slope, the rack geometry and the rack porosity, was explored. In addition, a novel approach to determine the discharge coefficient of a rack structure was developed. Finally, the intake channel below the bottom rack was investigated and several interesting features were found, including a significant flow instability that may have a strongly adverse effect on the rack performance.

Kumar et al. [14] carried out an experimental study on the discharge characteristics of a trench weir consisting of flat bars under free and submerged flow. They evolved the following relationship for discharge ratio $(\mathrm{Cd})$ based on observation and under constant conditions.

$C_{d}=0.471-0.124 \times \ln \left(\frac{S}{t}\right)-0.194 \times S_{r}-0.01 \times\left(\frac{\omega}{t}\right)$

Where $\mathrm{S}$ is clear spacing of rack bars, $\mathrm{t}$ represents the thickness of flat bars, $S_{r}$ stands for the slope of rack and $\omega$ is width of flat bars. They compared discharge ratio obtained from derived relation with the experimental data.

Kamanbedast and Shafai Bejestan [12] conducted experimental tests, in which they developed the following equation for discharge coefficient:

$C_{d}=0.223 \varepsilon^{-0.79} \mathrm{Fr}^{-0.295}\left(\frac{\emptyset}{L}\right)^{0.054}\left(\frac{Y_{1}}{L}\right)^{-0.0043}$

Where $\mathrm{Cd}$ is the coefficient discharge, $\varepsilon$ represents the area opening, $F_{r}$ stands for the Froude number, $\varnothing$ represents the bar diameter, $Y_{1}$ stands for the flow depth and $\mathrm{L}$ is the length of rack.

Josiah et al [11] performed a set of experiments in order to develop a methodology to estimate head loss through trash racks in open channel by considering the variable parameters such as bar diameter, clear spacing between bars, inclination angle and unit discharge. Head loss during trash rack is a key parameter to design geometrical arrangement of the bars. Josiah et al. proposed a new head loss equation based on the experimental findings to estimate the head loss through trash racks made up of circular bars.

$\frac{\Delta h}{V^{2}}=0.1923(\sin \alpha)^{0.05}(P)^{0.15}\left(\frac{q g}{V^{3}}\right)^{1.56}$

$\overline{2 g}$

Where $\mathrm{V}=$ approach velocity $\alpha=$ inclination angle from channel bed $\mathrm{P}=$ blockage ratio $\mathrm{q}=$ unit discharge Bina and Saghi [2] obtained the discharge coefficient by setting different discharges of sediment and clean water flow over bottom intakes and derived a dimensionless relation for discharge coefficient. A rectangular channel with 8 meters long and $0.4 \mathrm{~m}$ wide and three kinds of bottom grids with three opening ratios of 0.3 , 0.35 and 0.4 were built. Bottom grids were placed at the bottom of the channel with three different slopes $(20 \%, 30 \%$, and $56 \%)$. Sediment was sized to transport as bed load. They derived relations for the discharge coefficient for both sediment and clean water flow.

In the classical numerical modeling authors considered one-dimensional and two-dimensional models to analyse the hydraulic of turbulent flow and sediment transport. Nevertheless, over the bottom intakes, the flow becomes highly three-dimensional so that three-dimensional models were developed and considered (Castillo \& Carrillo [4]).

Kuntzmann and Bouvard [16] presented a first computational approach for the free-surface profile over bottom racks by assuming constant energy head and a conventional orifice equation. The spatial distribution of discharge as a function of the streamwise coordinate resulted in an ordinary differential equation of the sixth degree, which was solved for the horizontal bottom rack.

Castillo et al. [5] carried out numerical simulations with CFD methodology. They analyzed the increment in the wetted rack length due to the sediment transport. Different sediment concentrations, from $1.0 \%$ to $5.0 \%$ in volume, void ratios from 0.16 to 0.60 , flow rates, and rack slopes were all considered.

Although it seems that bottom intake has been studied in the past, there are so many questions regarding the estimating diverted discharge of bottom intakes to design a structure with optimum or desired intake ratio 
using numerical models with minimum cost. Therefore, the purpose of the present study is to investigate the effects of geometrical parameters of bottom intake and to approach flow conditions on the discharge coefficient and to contribute with new ideas for better structure design.

\section{Governing equations:}

The governing equations for the flow in a river with a lateral outflow through a bottom screen are as follow. Hosseini et al. in 2019 investigated on energy equation [8]:

Continuity equation:

$-\frac{d Q}{d x}=Q_{i}=C d \cdot \varepsilon \cdot \sqrt{2 g E}$

Energy equation:

$\frac{\mathrm{dy}}{\mathrm{dx}}=\frac{S o-S f-\left(\frac{a Q}{g A^{2}}\right)\left(\frac{d Q}{d x}\right)}{1-F r^{2}}$

In this equation:

$\mathrm{Q}$ is the discharge in the main channel; Qi is the diverted flow discharge (passing through bottom rack); $\varepsilon$ is the opening ratio of the screen; $C_{d}$ is discharge coefficient; $\mathrm{E}$ is the specific energy of the flow over the screen and is the sum of the flow depth (y) and velocity head $\left(\frac{V^{2}}{2 g}\right)$; Y is the flow depth on the screen; So is the screen slope; $S f$ is the slope of energy grade line; A is the flow area cross section in the main channel; $\mathrm{Fr}$ is the Froude number which is defined as $v / g y$ in which $\mathrm{v}$ is the flow velocity.

To determine the water surface profile over the screen, both equations must be solved. The analytical solution for these equations is possible through use of a few assumptions. The first assumption is that since the length of bottom rack generally is short, consequently the effect of channel and friction slopes on the flow profile can be assumed to be negligible. This assumption reveals that the value of specific energy (E) is constant. The second assumption is that the channel shape is wide and the discharge coefficient is constant. Applying these assumptions and substituting Eqation1 into each and calculating Q from specific energy definition which is $\mathrm{zg}$ by $Q=B y \sqrt{2 g(E-y)}$ and rearranging the terms in the resulting equation, one obtains:

$\frac{\mathrm{dy}}{\mathrm{dx}}=\frac{2 \varepsilon C d \sqrt{E(E-y)}}{3 y-2 E}$

Integration of Equation 3 yields:

$x=-\frac{y}{\varepsilon C d} \sqrt{1-\frac{y}{E}}+$ constant

The constant of integration can be determined from the flow conditions at the upstream of the bottom rack which yields:

$x=\frac{E}{\varepsilon C d}\left(\frac{y 1}{E} \sqrt{1-\frac{y 1}{E}}-\frac{y}{E} \sqrt{1-\frac{y}{E}}\right)$

Therefore, it can be seen that discharge coefficient is an important factor in determining the intake flow discharge (Equation5) and water surface computations (Equation2).

\section{Dimensional analysis:}

Before setting the numerical simulation of experimental tests, a general relationship has to be developed. This can be done by using the dimensional analysis. Discharge coefficient $(C d)$ can be shown as follows:

$C_{d}=f_{1}\left(\rho, \mu, g, \varepsilon, s_{L}, L, y_{0}, V_{0}, \frac{e_{l}}{d}\right)$ 
Where $C_{d}$ is discharge coefficient; $\rho$ is the specific mass of water; $\mu$ is dynamic viscosity of the fluid; $\mathrm{g}$ is acceleration of gravity; $\varepsilon$ is the opening ratio; $y_{0}$ is depth of approaching flow; L is the rack length; $V_{0}$ is approaching flow velocity; $e_{l}$ stands for clear space of longitudinal bars; $\mathrm{d}$ is the bar diameter and $s_{L}$ for longitudinal slope of bottom intake. By applying the dimensional analysis (buckingham $\pi$ theorem), the non-dimensional equation can be developed (Equation 7). After simplification of above equation and eliminating the parameters with constant values in this study, following function can be obtained:

$$
C_{d}=f\left(\frac{\mu}{\rho V_{O} y_{o}}, \frac{g y_{o}}{V_{o}^{2}}, \varepsilon, s_{L}, \frac{L}{y_{o}}, \frac{e_{l}}{d}\right)
$$

\section{Experimental devive:}

Bina's physical model consists of a $0.4 \mathrm{~m}$ wide, $0.5 \mathrm{~m}$ deep and $8 \mathrm{~m}$ long flume with Plexiglas walls that allows for the inspection of the flow and perform minimum roughness. Three kinds of bottom screens with different opening ratio of $0.3,0.35$ and 0.4 were built and installed at the end of the flume $(30 \mathrm{~cm}$ long and $40 \mathrm{~cm}$ wide). Bottom screens are made of longitudinal and cross bars (grid) with circular shape $(\emptyset 8 \mathrm{~mm})$. A pipe was connected to the bottom of the flume to transport the diverted water into the sump. A v-notch weir at the downstream end of the channel, measures the discharge and the discharge passing through the screen. Fig. 2 shows the sketch of the experimental setup.

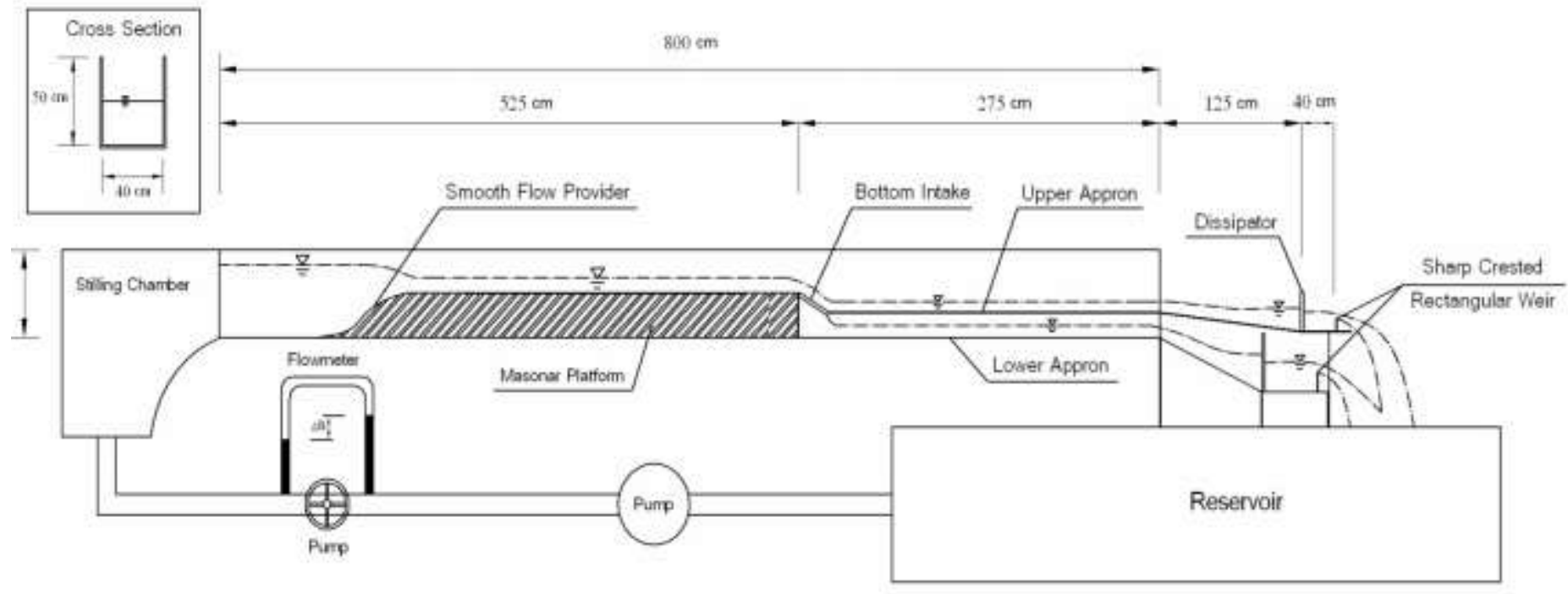

Figure 2. Sketch of the experimental setup.

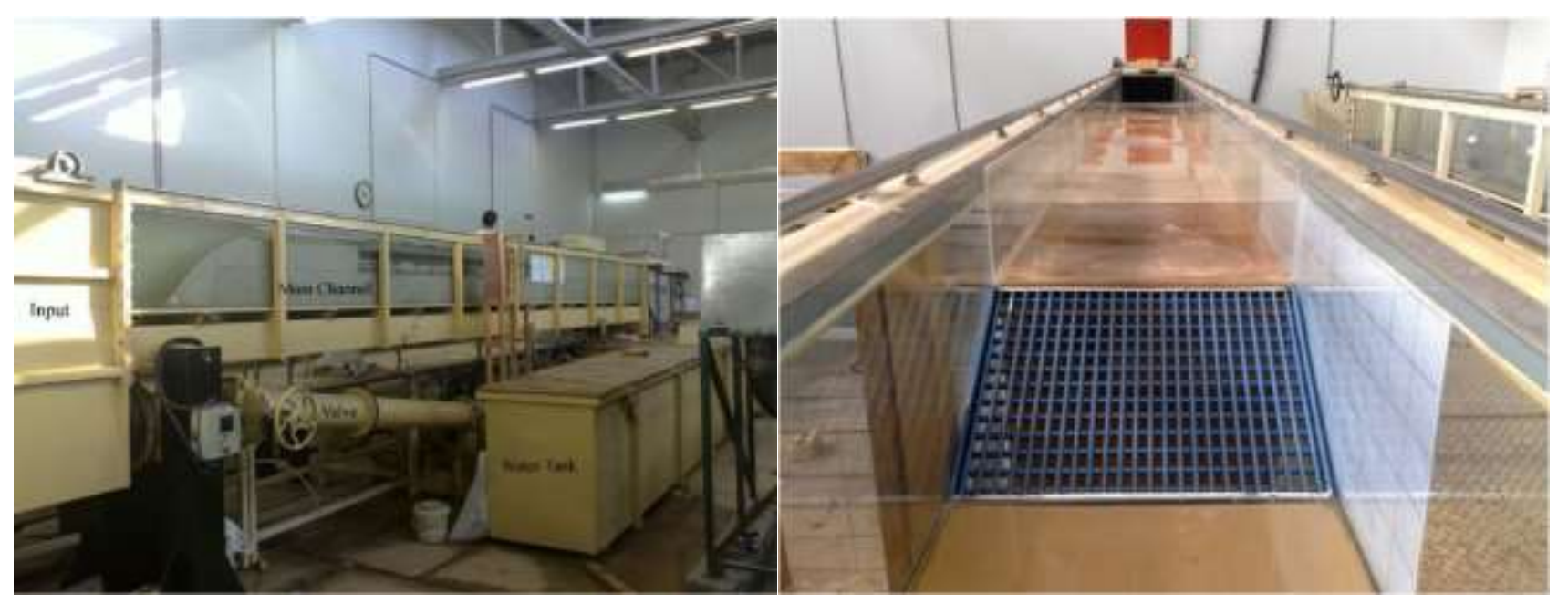

Figure 3. View of experimental model.

\section{Experimental procedure:}

After installing one of the bottom racks at the desired slope, the flow was allowed to enter the flume by gradual opening of the entrance valve until the flow discharge reaches the desired discharge (Fig. 3). This situation was kept constant for one hour. During this time, water surface elevation was measured in the 
flume, especially above the bottom rack. The diverted flow discharge was also measured. Then, flow discharge in the flume was increased and the same variables were measured. The same procedure was followed for three more discharges. Afterwards, the bottom rack was installed at a new slope and the above mentioned tests were repeated. The above procedures were followed by installing a new model of bottom rack with three new opening ratio.

To investigate the performance of bottom racks when the sediment is passing over the rack tests have been repeated in more restricted condition. In these series sediment was placed on the bed of upstream flume of the bottom rack with non-uniform gradation (combination of D75=5mm and D75=8mm) which is transported as bed-load under the range of allowed discharges (Fig. 4). The series of tests were conducted under the same conditions as clean flow.
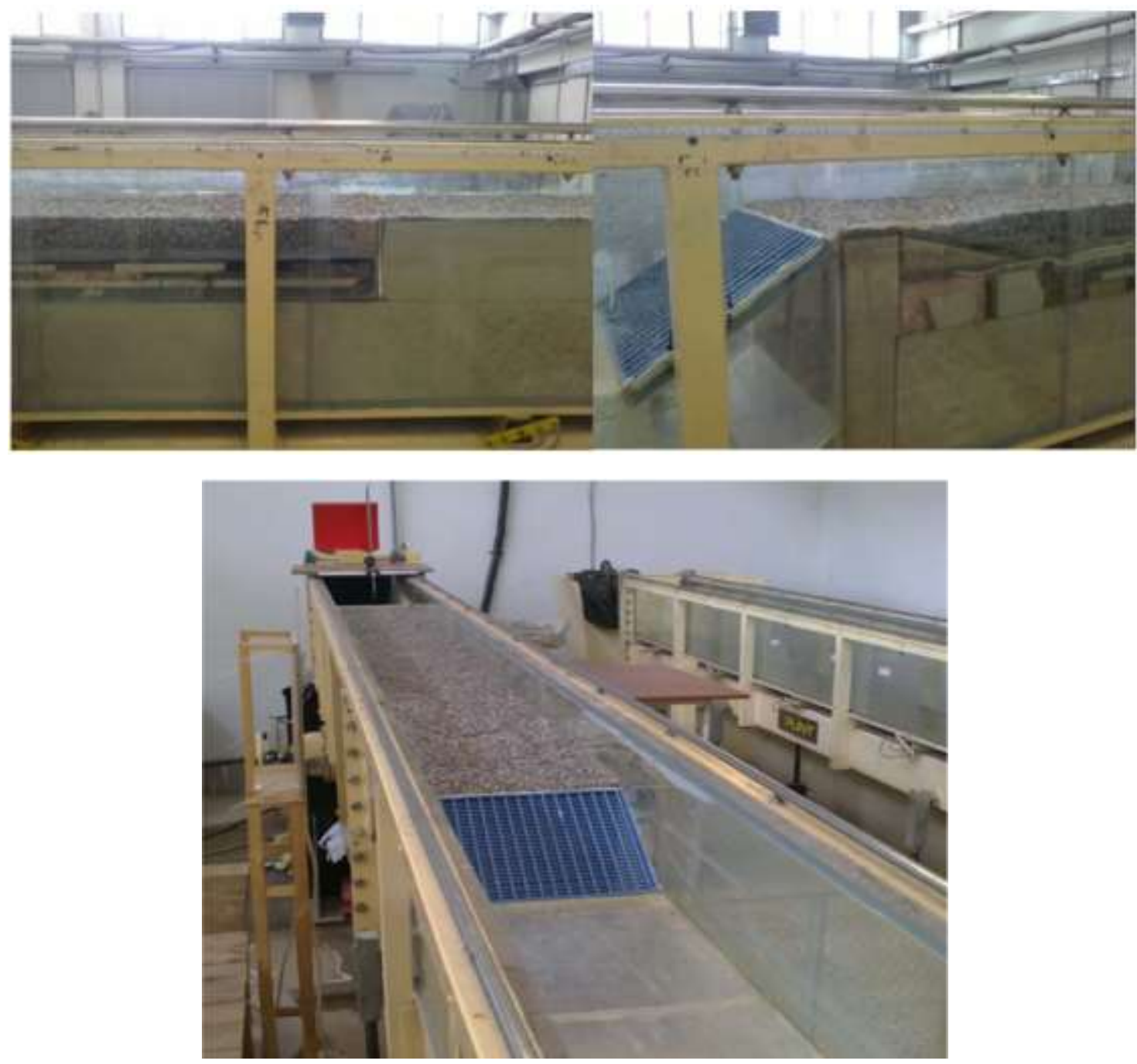

Figure 4.view of sediment bed load considerations.

\section{Simulation:}

\section{Numerical model:}

The computational fluid dynamics (CFD) programs solve the fluid mechanic problems, providing lots of data and flexibility. However, the numerical models still present a level of mismatch when modelling some hydraulic phenomena. Hence, it is necessary to validate numerical results with experimental data. Some certain Laboratory tests were considered to validate simulations in order to evaluate the accuracy of the finite-element scheme program FLOW-3D.

The experimental conditions modeled in Flow3-d Software with suitable boundary conditions. Parameters such as roughness, size of computational cell, turbulence transport equation, Bed Load Transport equation and bed load coefficient calibrated to match the experimental and numerical results. 

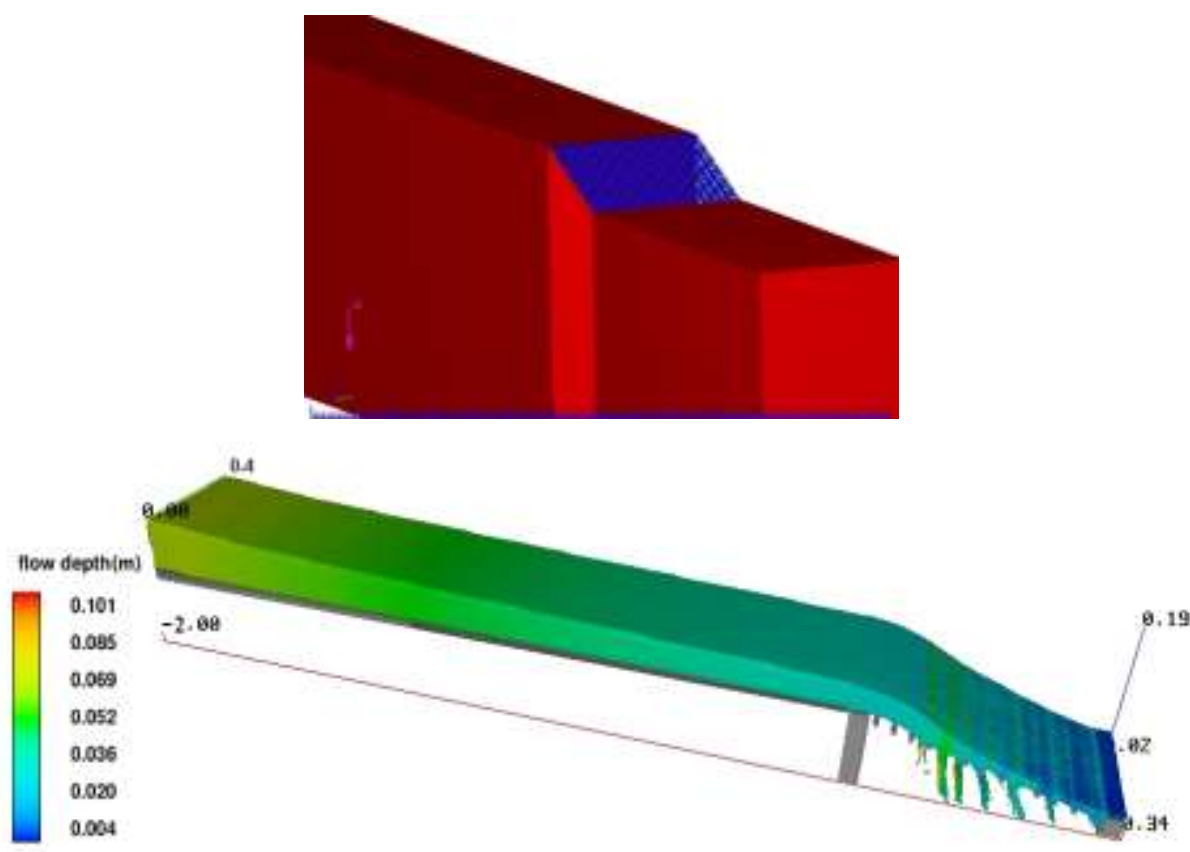

Figure 5. View of a modelling test.

\section{Boundary conditions:}

It's important to set suitable boundary conditions for computional enviromet to apply exact lobratoar conditions on model. In this case, Volume Flow Rate boundary condition considered for inlet of the mesh grid that provide the possibility to set the discharge and depth of the inlet flow. WALL boundary condition setted for the flume wall that was made of plexiglas in the lobratoar. This type of boundary provides rigorous and zero-roughness (as what plexiglas provides). For the outlet faces of the grid, OUTFLOW boundery is considersd in order to observe the discharge of the diverted flow and remaining flow at the end of flume. Fig. 6 shows the considered boundry conditions of cumputional grid.

Zeidi et al. defined a robust way of assigning boundary condition, including assigning wall bounday condition, pressure difference boundary condition and velocity inlet boundary condition which is used in the current study [26].

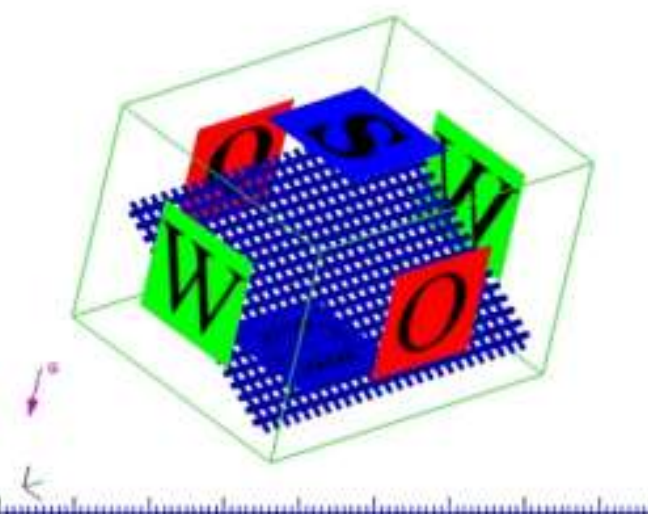

Figure 6. View of applied boundary condition.

\section{Mesh Size:}

To test the accuracy of the numerical simulations data, diverted discharges of the intake were compared by using different mesh sizes and thus obtaining mesh sizes sufficiently insensitive to the results (Table 1). The analysis was based on the diverted discharge obtained after stabilization of measured discharge with a tolerance of $0.005 \mathrm{l} / \mathrm{s}$. The comparison with the laboratory measurements shows good agreement for the mesh sizes smaller than $4 \mathrm{~mm}$.

Also it can be seen that $2.5 \mathrm{~mm}$ and $2 \mathrm{~mm}$ mesh sizes make tolerable differences in diverted discharge. As there are no outstanding differences between the results obtained with the smaller mesh size, the $2.5 \mathrm{~mm}$ mesh size is used to analyze the rest of the models (based on run-time considrations). The grid convergence method for selecting mesh sizes is used and inspiered by Zahani et al. and Zeidi et al. [21,27-29]. 
Table 1. Fluctuation of diverted discharge by calibrating mesh sizes.

\begin{tabular}{|c|c|c|c|c|c|c|c|}
\hline \multirow{3}{*}{ Test no. } & \multirow{2}{*}{$\begin{array}{c}\text { Experiment } \\
\text { al Qd }\end{array}$} & $\begin{array}{c}\text { size of } \\
\text { cell=6 } \\
\end{array}$ & $\begin{array}{c}\text { size of } \\
\text { cell=5 } \\
\mathrm{mm}\end{array}$ & $\begin{array}{c}\text { size of } \\
\text { cell=4 } \\
\mathrm{mm}\end{array}$ & $\begin{array}{c}\text { size of } \\
\text { cell=3 } \\
\mathrm{mm}\end{array}$ & $\begin{array}{c}\text { size of } \\
\text { cell=2.5 } \\
\mathrm{mm}\end{array}$ & $\begin{array}{c}\text { size of } \\
\text { cell=2 } \\
\mathrm{mm}\end{array}$ \\
\hline 81 & 25.5984 & 26.510 & 24.765 & 25.979 & 25.742 & 25.611 & 25.610 \\
\hline
\end{tabular}

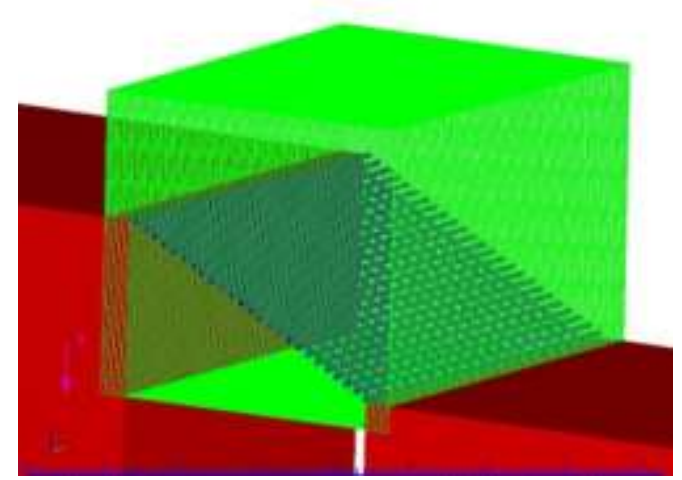

Figure 7. View of applied mesh grid.

\section{Turbulence Model:}

Due to the different behavior of the turbulence models in complex flow conditions around the bottom intake, the influence of the turbulence model has also been tested with four of the turbulence models: the standard k- $\varepsilon$ model, the ReNormalization Group (RNG), the Large Eddy Simulation (LES) model and the Prandtl's one-equation model. Three experimental tests are used and Table 2. compares the values of the numerical and experimental diverted discharge by using different turbulence models. For the cases considered, There are no outstanding differences between the four turbulence models and the experimental measurements. However, the RNG turbulence model made less difference between experimental and numerical diverted discharge.

Table 2. Comparison between numerical results of four turbulence models.

\begin{tabular}{|c|c|c|c|c|}
\hline $\begin{array}{c}\text { turbulence } \\
\text { model }\end{array}$ & Test no & Qd (Exp) & Qd (Num) & $\left(R^{2}\right)$ average \\
\hline \multirow{3}{*}{ Prandtl } & 66 & 19.5639 & 23.2153 & \multirow{3}{*}{0.973} \\
\hline & 81 & 25.5984 & 26.3646 & \\
\hline & 246 & 24.8094 & 28.2354 & \\
\hline \multirow{3}{*}{$\mathrm{k}-\varepsilon$} & 66 & 19.5639 & 22.1650 & \multirow{3}{*}{0.986} \\
\hline & 81 & 25.5984 & 26.4254 & \\
\hline & 246 & 24.8094 & 27.3645 & \\
\hline \multirow{3}{*}{ RNG } & 66 & 19.5639 & 20.5582 & \multirow{3}{*}{0.998} \\
\hline & 81 & 25.5984 & 25.9709 & \\
\hline & 246 & 24.8094 & 25.1139 & \\
\hline \multirow{3}{*}{ LES } & 66 & 19.5639 & 19.3657 & \multirow{3}{*}{0.990} \\
\hline & 81 & 25.5984 & 25.9932 & \\
\hline & 246 & 24.8094 & 24.2364 & \\
\hline
\end{tabular}




\section{Results and Discussion:}

The value of discharge coefficient was calculated from the following equation, using the measured data:

$C_{d}=\frac{Q_{i}}{\varepsilon \sqrt{2 g E}}$

Where E was computed from upstream flow conditions. Table 3. shows a summary of the experimental results.

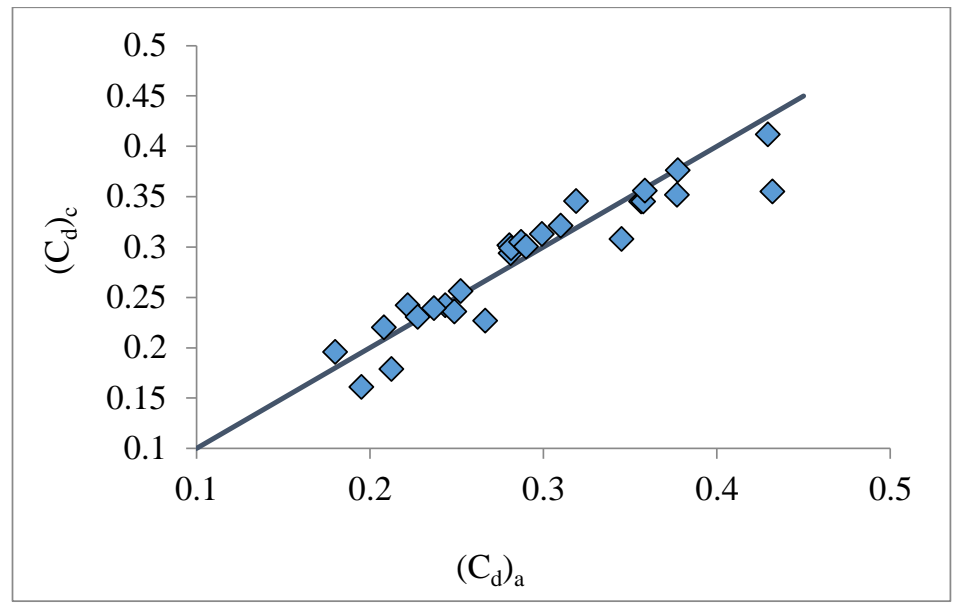

Figure 8. View of a modelling test.

Table 3. Summary of the results.

\begin{tabular}{|c|c|c|c|c|c|c|}
\hline $\begin{array}{c}\text { Test } \\
\text { no }\end{array}$ & $\boldsymbol{\varepsilon}$ & $\mathbf{F r}_{\mathbf{o}}$ & $\boldsymbol{Y}_{\boldsymbol{o}}(\mathbf{m m})$ & Slope\% & Re & $\begin{array}{c}\text { Cd } \\
\text { (experimental) }\end{array}$ \\
\hline 60 & 0.4 & 1.53 & 33 & 56.98 & 28701 & 0.1951 \\
\hline 66 & 0.4 & 2.28 & 47 & 56.98 & 72793 & 0.2219 \\
\hline 63 & 0.4 & 1.55 & 47 & 56.98 & 49550 & 0.2433 \\
\hline 103 & 0.4 & 1.57 & 49 & 27.24 & 53312 & 0.2811 \\
\hline 106 & 0.4 & 1.48 & 68 & 27.24 & 82322 & 0.3563 \\
\hline 100 & 0.4 & 1.54 & 35 & 27.24 & 31552 & 0.2082 \\
\hline 83.1 & 0.3 & 1.54 & 47 & 56.2 & 49059 & 0.2805 \\
\hline 233 & 0.4 & 1.54 & 48 & 21.16 & 50883 & 0.2813 \\
\hline 236 & 0.4 & 1.5 & 67 & 21.16 & 81691 & 0.3771 \\
\hline 230 & 0.4 & 1.53 & 31 & 21.16 & 26135 & 0.1799 \\
\hline 86.1 & 0.3 & 1.51 & 61 & 56.2 & 71047 & 0.3188 \\
\hline 80.1 & 0.3 & 1.55 & 35 & 56.2 & 31697 & 0.2487 \\
\hline 81 & 0.3 & 1.51 & 66 & 57.36 & 79985 & 0.432 \\
\hline 82 & 0.3 & 1.54 & 49 & 57.36 & 52222 & 0.345 \\
\hline 80 & 0.3 & 1.53 & 34 & 57.36 & 30141 & 0.2665 \\
\hline 256 & 0.3 & 1.5 & 67 & 20.14 & 81529 & 0.4295 \\
\hline 253 & 0.3 & 1.54 & 53 & 20.14 & 58837 & 0.3775 \\
\hline 250 & 0.3 & 1.54 & 40 & 20.14 & 38688 & 0.3101 \\
\hline 76 & 0.4 & 1.51 & 65 & 57.36 & 78279 & 0.2872 \\
\hline 73 & 0.4 & 1.53 & 48 & 57.36 & 50546 & 0.2524 \\
\hline
\end{tabular}




\begin{tabular}{|c|c|c|c|c|c|c|}
70 & 0.4 & 1.51 & 34 & 57.36 & 29723 & 0.2124 \\
\hline 93 & 0.4 & 1.54 & 48 & 27.34 & 50747 & 0.2901 \\
\hline 97 & 0.4 & 1.5 & 63 & 27.34 & 74414 & 0.3575 \\
\hline 90 & 0.4 & 1.53 & 35 & 27.34 & 31375 & 0.2277 \\
\hline 243 & 0.4 & 1.55 & 49 & 21.5 & 52748 & 0.299 \\
\hline 246 & 0.4 & 1.49 & 64 & 21.5 & 75651 & 0.3584 \\
\hline 240 & 0.4 & 1.54 & 35 & 21.5 & 31586 & 0.2369 \\
\hline
\end{tabular}

For clean water flow, based on numerical results (diverted discharges), discharge coefficient of each test is calculated. By multiple linear fitting of dimensionless parameters, using SPSS Statistical software, the following relation is obtained for discharge coefficient:

$C_{d}=0.759-0.543(\varepsilon)-0.03 *\left(\frac{L}{y_{o}}\right)-0.013\left(\frac{e_{L}}{d}\right)-0.00147\left(S_{L}\right)$

$R M S E=7.75 \%, R^{2}=93.5 \%$

This relation is based on numerical results of Flow-3d. In this relation, the effect of Reynolds number on discharge coefficient has been neglected in comparison with Bina's proposed relation.

Discharge coefficient values of proposed relation in this study against experimental values of discharge coefficient plotted in Fig. 8. Also table 4. is a comparison between measured diverted discharge and computed diverted discharge using the proposed relation. It can be seen that accuracy of proposed relation is acceptable.

Table 4. Comparison between measured diverted discharge and computed diverted discharge using the proposed relation.

\begin{tabular}{|c|c|c|c|}
\hline Row & $\begin{array}{c}\text { Qd } \\
\text { (Experimental) }\end{array}$ & $\begin{array}{c}\text { Qd } \\
\text { (proposed } \\
\text { relation) }\end{array}$ & Error\% \\
\hline 1 & 11.1834 & 10.838 & -17.4 \\
\hline 2 & 19.5639 & 21.396 & 9.4 \\
\hline 3 & 16.7888 & 16.743 & -0.3 \\
\hline 4 & 19.9222 & 20.86 & 4.7 \\
\hline 5 & 28.8521 & 28.001 & -2.9 \\
\hline 6 & 12.3353 & 13.072 & 6.0 \\
\hline 7 & 14.18 & 15.495 & 9.3 \\
\hline 8 & 30.537 & 28.574 & -6.4 \\
\hline 9 & 10 & 10.909 & 9.1 \\
\hline 0 & 18.1585 & 20.003 & 10.2 \\
\hline 11 & 10.8832 & 10.489 & -3.6 \\
\hline 12 & 17.8102 & 16.141 & -9.4 \\
\hline 13 & 11.4497 & 9.894 & -13.6 \\
\hline 14 & 25.5964 & 24.943 & -2.6 \\
\hline 15 & 20.2832 & 20.55 & 1.3 \\
\hline 16 & 14.4968 & 15.256 & 5.2 \\
\hline 17 & 20.2832 & 21.537 & 6.2 \\
\hline 18 & 15.4633 & 15.676 & 1.4 \\
\hline 19 & 10.8732 & 9.145 & -15.9 \\
\hline
\end{tabular}




\begin{tabular}{|c|c|c|c|}
\hline 20 & 17.8102 & 18.42 & 3.4 \\
\hline 21 & 24.81 & 23.919 & -3.6 \\
\hline 22 & 11.8894 & 12.032 & 1.2 \\
\hline 23 & 18.504 & 19.462 & 5.2 \\
\hline 24 & 12.3353 & 12.526 & 1.5 \\
\hline mean & 17.25039 & 17.26171 & 6.4 \\
\hline
\end{tabular}

For the sediment flow, the following relation is obtained for discharge coefficient:

$R M S E=13.35 \%, R^{2}=80 \%$

$$
C_{d}=0.652-0.528(\varepsilon)-0.019 *\left(\frac{L}{y_{o}}\right)-0.00169\left(S_{L}\right)
$$

Table 5. shows a comparison between measured discharge coefficient and computed discharge coefficient using the proposed relation for sediment flow. As it can be seen, proposed relation led to a mean of $4.36 \%$ difference with measured discharge coefficient that is acceptable and confirms the function of numerical model. Also discharge coefficient of proposed relation plotted against measured discharge coefficient in figure 9.

Table 5. comparison between measured discharge coefficient and computed discharge coefficient using the proposed relation for sediment flow.

\begin{tabular}{|c|c|c|c|c|c|c|}
\hline Test no & $\varepsilon$ & y0 & slope & Cd(measured) & $\begin{array}{c}\text { Cd(fitting } \\
\text { relation) }\end{array}$ & \% error \\
\hline Mog-8 & 0.302 & 0.054 & 56.42 & 0.286101 & 0.29163864 & 1.92 \\
\hline 8 & 0.356 & 0.054 & 56.42 & 0.294085 & 0.26312664 & -10.54 \\
\hline 10 & 0.302 & 0.05 & 23.45 & 0.346376 & 0.3389135 & -2.17 \\
\hline 12 & 0.356 & 0.05 & 23.45 & 0.30924 & 0.3104015 & 0.39 \\
\hline 6 & 0.404 & 0.052 & 56.42 & 0.223725 & 0.23372282 & 4.47 \\
\hline 14 & 0.404 & 0.051 & 23.45 & 0.282936 & 0.28729279 & 1.56 \\
\hline 89 & 0.3021 & 0.044 & 56.42 & 0.285722 & 0.26759595 & -6.33 \\
\hline 81 & 0.3021 & 0.052 & 56.42 & 0.264434 & 0.28823582 & 9.00 \\
\hline mog5 & 0.3021 & 0.04 & 56.42 & 0.247352 & 0.2546414 & 2.95 \\
\hline \multicolumn{7}{|c|}{ mean } \\
\hline
\end{tabular}

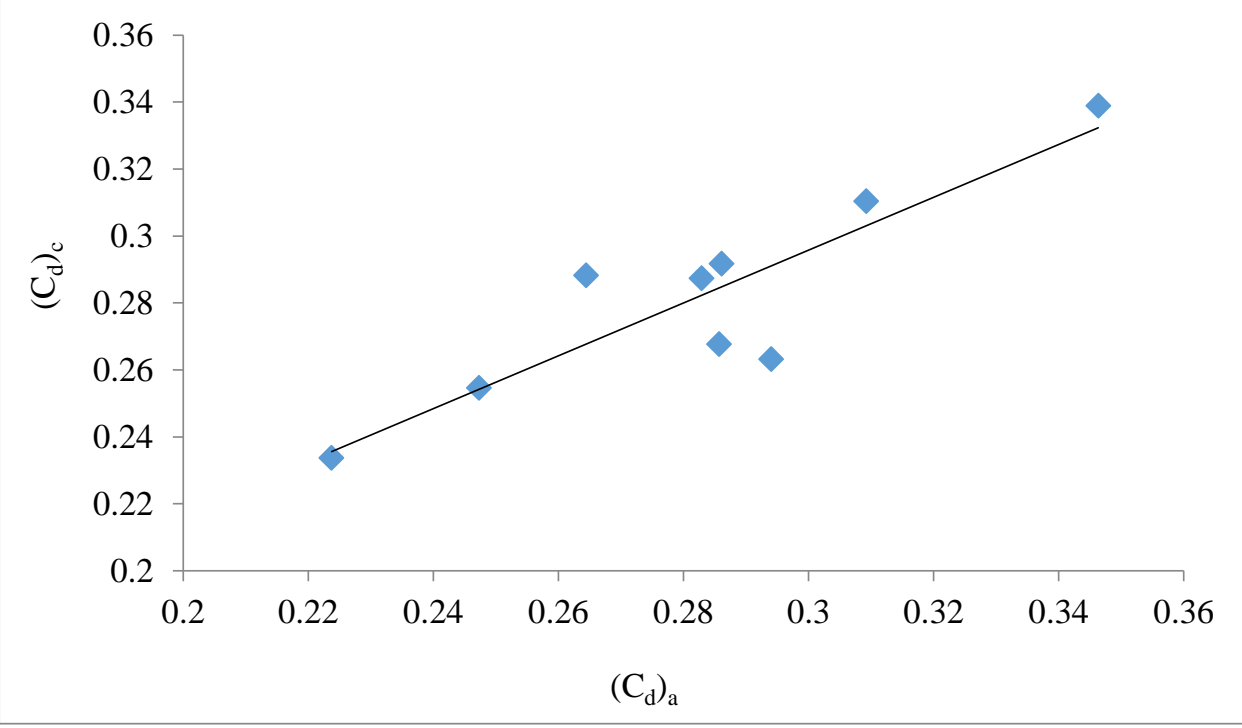

Figure 9. discharge coefficient of proposed relation for sediment flow $\left(\mathrm{Cd}_{\mathrm{c}}\right)$ against measured discharge coefficient $\left(\mathrm{Cd}_{\mathrm{a}}\right)$ 
Ratio of diverted discharge to total input discharge $\left(\frac{Q_{d}}{Q_{t}}\right)$ against total input discharge $\left(Q_{t}\right)$ for every three opening ratio of bottom intakes is plotted in Figures 10, 11 and 12.

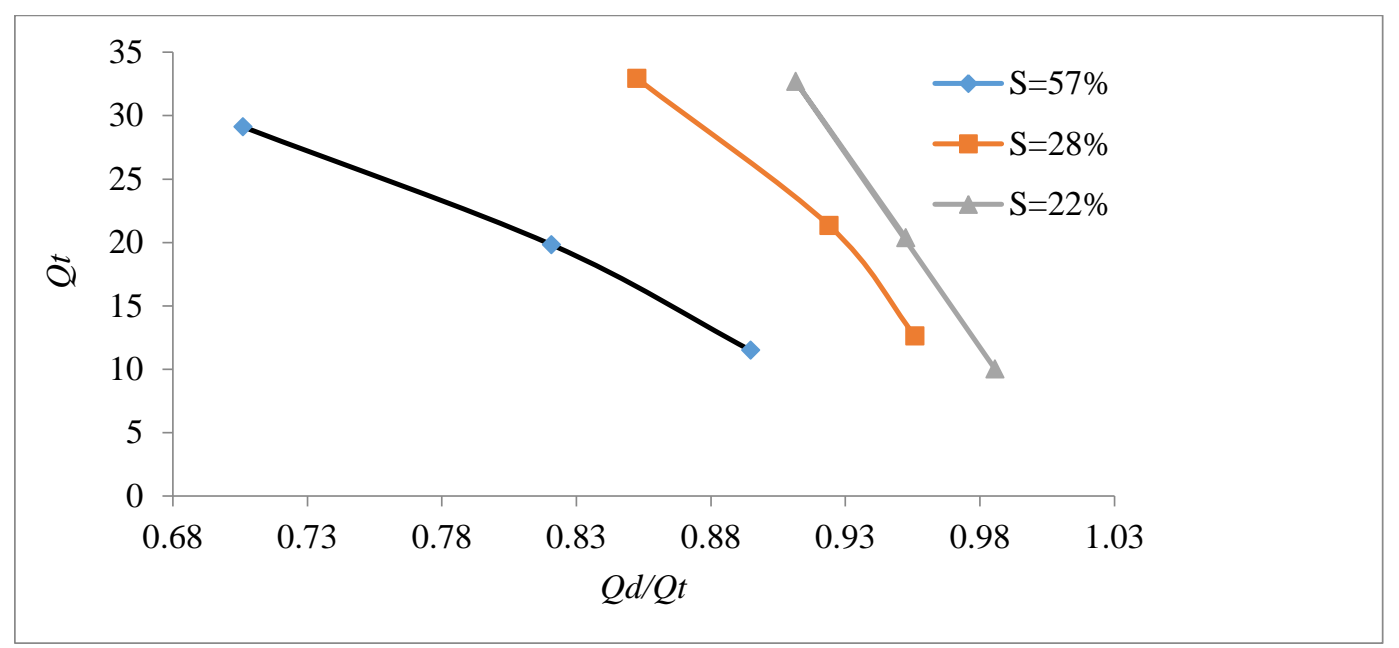

Figure 10. Ratio of diverted discharge to total input discharge against total input discharge for $\varepsilon=0.3$

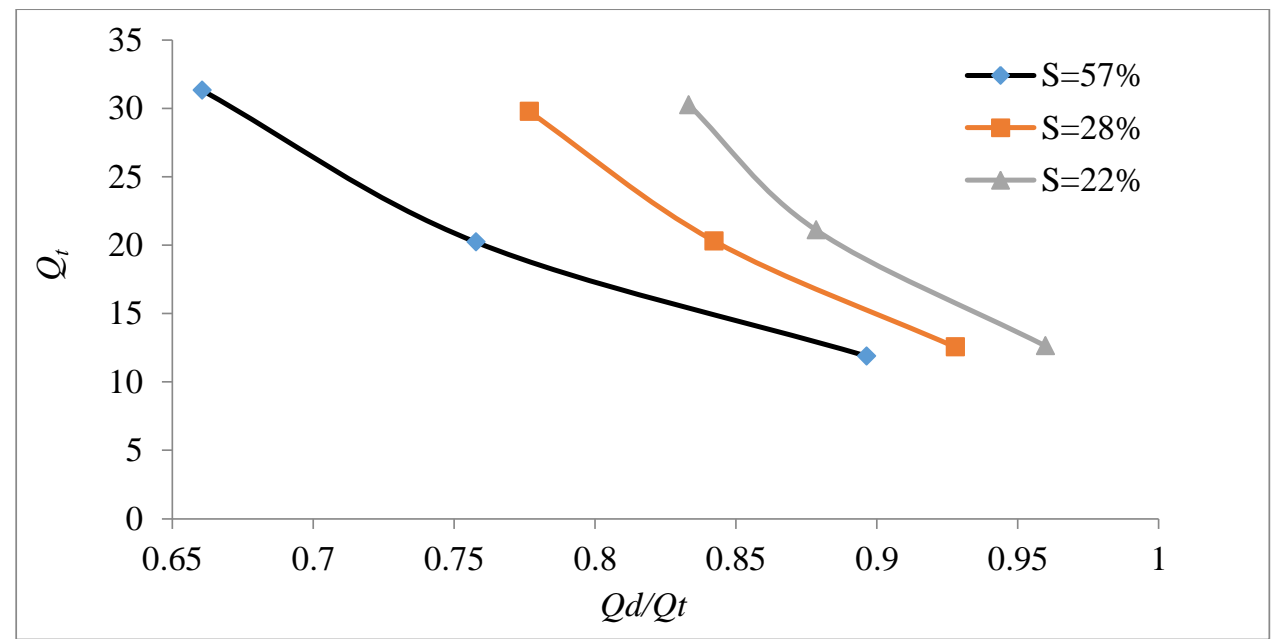

Figure 11. Ratio of diverted discharge to total input discharge against total input discharge for $\varepsilon=0.35$

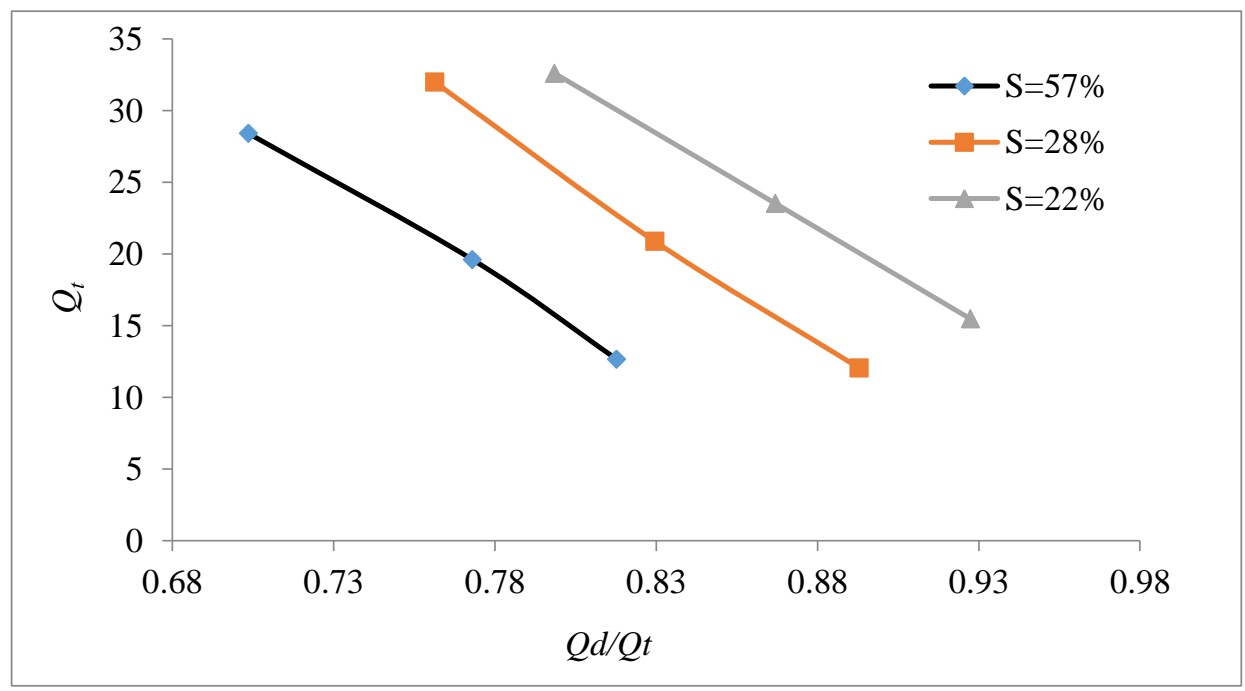

Figure 12. Ratio of diverted discharge to total input discharge against total input discharge for $\varepsilon=0.4$

\section{Conclusions:}


Verified relations for discharge coefficient obtained:

\begin{tabular}{|c|c|c|c|}
\hline $\begin{array}{c}\text { Sediment/clean } \\
\text { flow }\end{array}$ & Fitting relation to estimate discharge coefficient & $\begin{array}{c}\text { Average } \\
\text { error }\end{array}$ & $\begin{array}{c}\text { Standard } \\
\text { deviation }\end{array}$ \\
\hline Clean flow & $C_{d}=0.759-0.543(\varepsilon)-0.03 *\left(\frac{L}{y_{o}}\right)-0.013\left(\frac{e_{L}}{d}\right)$ & $6.4 \%$ & 0.0314 \\
\hline Sediment flow & $C_{d}=0.652-0.528(\varepsilon)-0.019 *\left(\frac{L}{y_{o}}\right)-0.00169\left(S_{1}\right)$ & $4.3 \%$ & 0.0313 \\
\hline
\end{tabular}

- Estimating discharge coefficient with proposed relation for clean flow led to a mean error of $6.4 \%$ in comparison with measured values.

- Estimating discharge coefficient with proposed relation for sediment flow led to a mean error of $4.3 \%$ in comparison with measured values.

- Following factors increases discharge coefficient of bottom intake:

1) Less longitudinal slope of bottom intake, 2) more opening ratio of bottom screen and 3) Less Froude number.

\section{References:}

[1] Bianco, G. and Ripellino, P. G. 1994. Attualita delle opera di presa a traversa derivante e studio con modello idraulico di un tipo di griglia suborizzontal. Idrotecnica 21(1):3-12 (in Italian).

[2] Bina, K., Saghi, H. (2017). Experimental Study of Discharge Coefficient and Trapping Raito in Mesh-Panel Bottom Rack for Sediment and Non-Sediment Flow and Supercritical Approaching Conditions. Journal of Experimental Thermal and Fluid Science. Vol. 88: 171-186

[3] Brunella, S., W. Hager and H.E. Minor. (2003). Hydraulics of bottom rack intake. J. Hydraul. Eng. ASCE 129(1): 2-10.

[4] Castillo, L.G.; Carrillo, J.M. Comparison of methods to estimate the scour downstream of a ski jump. Int. J. Multiph. Flow 2017, 92, 171-180.

[5] Castillo, L., Garcia, J., \& Carrillo, m., Qin, Q. (2016). Experimental and numerical study of bottom rack occlusion by flow with gravel-sized sediment. Application to ephemeral streams in semi-arid regions. Journal of Water, 10.3390/w8040166.

[6] Dagan, G. Notes sur le calcul hydraulique des grilles par-dessous. La Houille Blanche 1963, 18, 59-65. (In French)

[7] Drobir, H.; Kienberger, V.; Krouzecky, N. The wetted rack length of the Tyrolean weir. In Proceedings of the IAHR-28th Congress, Graz, Austria, 22-27 August 1999.

[8] Hosseini, D., Torabi, M., \& Moghadam, M. A. (2019). Preference assessment of energy and momentum equations over 2D-SKM method in compound channels. Journal of Water Resource Engineering and Management, 6(1), 24-34.

[9] Escande, L. 1955. Prise d'eau a travers une grille nouveau complements d'hydraulique. Publications Scientifiques et Techniques du Ministère de l'Air, Paris 302(2):59-63 (in French).

[10] García, J.T. Estudio Experimental y Numérico de los Sistemas de Captación de Fondo. Ph.D. Thesis, Universidad Politécnica de Cartagena, Murcia, Spain, 2016. (In Spanish) 
[11] Josiah, N.R., Tissera, H.P.S., and Pathirana, K.P.P. (2016). An Experimental Investigation of Head loss through Trash Racks in Conveyance Systems. Engineer- Vol. XLIX, No.01, PP. [1-8].

[12] Kamanbedast, A. and Shafai Bejestan, M. 2008. Effects of slope and area opening on the discharge ratio in bottom intake structures. Journal of Applied Sciences 8(14):2631-2635.

[13] Kamanbedast, A. et al. 2009. Investigation of the hydraulic and sediment at bottom intake for hydro-power with physical modeling. Int. Conference CESSE 2009, Venice, Italy.

[14] Kumar, S., Ahmad, Z., Umesh, C., Mittal, M.K. (2010). Discharge characteristics of a trench weir. Flow Measurement and Instrumentation 21: 80-87.

[15] Kumar, S., Ahmad, Z. (2015). Experimental investigation on ingestion of sediment into trench weirs. ISH Journal of Hydraulic Engineering.

[16] Kuntzmann, J. and Bouvard, M. 1954. Étude théorique des grilles de prises d'eau du type. La Houille Blanche 9(9/10):569-574 (in French).

[17] Noseda, G. 1956. Correnti permanenti conportata gressivamentse decrescente d'efluenti su griglie di fondo. L'Energia Elettrica 33(1):41- 51; 33(6):565-588 (in Italian).

[18] Orth, J., Chardonnet, E. and Meynardi, G. 1954. Étude de grilles pour prises d'eau du type. La Houille Blanche 9(6):343-351 (in French).

[19] Racet-Madoux, X., Bouvard, M., Molbert, J. and Zumstein, J. 1955. Quelques realizations récentes de prises. In Dessous a haute altitude.

[20] Righetti, M. \& S. Lanzoni. (2008). Experimental study of the flow field over bottom intake racks. J. Hydraul. Eng. ASCE 134: 15-22.

[21] Zahabi, H., Torabi, M., Alamatian, E., Bahiraei, M., \& Goodarzi, M. (2018). Effects of Geometry and Hydraulic Characteristics of Shallow Reservoirs on Sediment Entrapment. Water, 10(12), 1725.

[22] Stefano, C., Ferro V., 2013. Experimental Study of the Stage-Discharge Relationship for an Upstream Inclined Grid with Longitudinal Bars. Journal of American Society of Civil Engineers. 10.1061/(ASCE)IR.19434774.0000598

[23] Vargas, V. Tomas de fondo. In Proceedings of the XVIII Congreso Latinoamericano de Hidráulica, Oaxaca, Mexico, 6-10 October 1998. (In Spanish)

[24] Torabi, M., Hamedi, A, Alamatian, E., Zahabi, H. (2019). The Effect of Geometry Parameters and Flow Characteristics on Erosion and Sedimentation in Channel's Junction using Finite Volume Method. International Journal of Engineering and Management Research (IJEMR), 9(2), 115-123.

[25] Hamedi, A., \& Ketabdar, M. (2016). Energy loss estimation and flow simulation in the skimming flow regime of stepped spillways with inclined steps and end sill: A numerical model. International Journal of Science and Engineering Applications, 5(7), 399-407.

[26] Zeidi, S. M. J, Mahdi, M., 2015, "Evaluation of the physical forces exerted on a spherical bubble inside the nozzle in a cavitating flow with an Eulerian/Lagrangian approach", European journal of physics, 136(6).

[27] Zeidi, S M J and Mahdi M, 2014, "Effects of nozzle geometry and fuel characteristics on cavitation phenomena in injection nozzles", The 22st Annual International Conference on Mechanical Engineering-ISME 2014, available online at "http://www.civilica.com/EnPaper-ISME22_394.htmlhttp://www.civilica.com/EnPaper--ISME22_394.html”.

[28] Zeidi, S M J and Mahdi M, 2015, "Investigation effects of injection pressure and compressibility and nozzle entry in diesel injector nozzle's flow" J. Appl. Comp. Mech. 2 83-94. 
[29] Zeidi, S M J and Mahdi M, 2015, "Investigation of viscosity effect on velocity profile and cavitation formation in diesel injector nozzle", 8th International Conference on Internal Combustion Engines 2014, ISBN 978-600-91530, available online at http://www.civilica.com/EnPaper-ICICE08_055.html 